\title{
Food technology divides British teachers
}

London. If Britain's technology is eventually regenerated, historians may place the beginning of the trend in 1993, and identify its vehicle as the soggy flapjacks (cereal bars) now being produced in British schools as part of the new technology curriculum.

For some months, 15-year-olds throughout England and Wales, male and female alike, have been struggling to devise a recipe for a "high energy snack", one of the required tasks in the technology curriculum introduced three years ago. But the question of whether this is a wise use of students' and teachers' time has helped to trigger a conflict between teachers and the government just as bitter as recent rows over the compulsory assessment of basic skills.

The problem started in 1988, when the government decided that all children should be required to spend part of their school career studying technology. Home economics teachers, seeing the prospect of their subject being marginalized as a result, fought - and won - a battle to ensure that cooking and nutrition, under the label of "food technology", should be included in the new

compulsory curriculum, introduced in 1990.

Three years on, the teaching of technology in schools is in disarray. Last year, faced with complaints from both teachers and potential employers of an unwieldy and unfocused syllabus, the government promised to introduce a new revised curriculum from the autumn of 1994 for children up to the age of 13 , and in the following year for the 14-to-16 age group.

Last week, however, faced with continuing disagreement over what and how much this curriculum should contain, John Patten, the Secretary of Education, announced that the introduction of new technology curricula would be delayed for another year in each case, to provide time for further revision. Students will still take the heavily criticized existing courses next year, but will not now be assessed on them.

At the heart of the dispute is the lack of a sharp definition of what "technology" meant when the national curriculum was established. Last December, the Department for Education published a set of proposed changes that attempts to provide a tighter

\section{Recession causes fall in R\&D spending}

London. Figures released last week by the Organization for Economic Cooperation and Development (OECD) confirm that the economic recession has caused a significant

slowing down in the research and development (R\&D) expenditures of all advanced industrialized nations.

Spending on R\&D in the United States, measured in prices adjusted for inflation, fell by 0.3 per cent between 1990 and 1991.

Average annual \% growth in gross domestic expenditure on $\mathbf{R} \& \mathbf{D}$ at constant prices

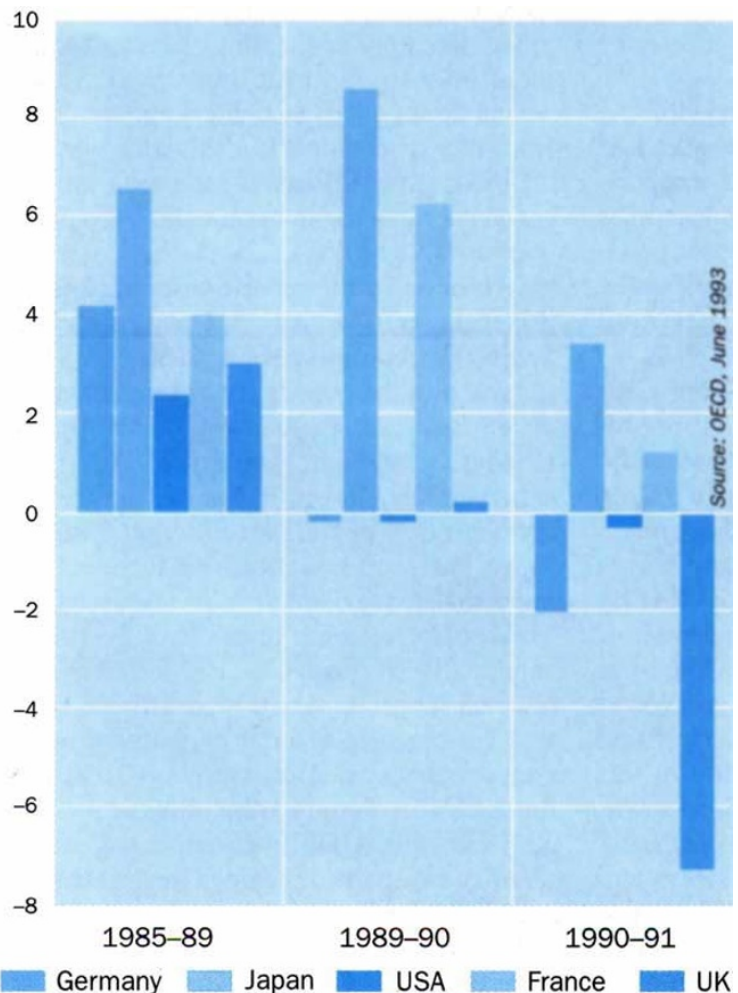
In Japan, R\&D continued to grow by 3.4 per cent in 1990 91; but this was in sharp contrast to an 8.6 per cent increase in the previous year, and it also resulted in total spending on R\&D dropping from 2.88 to 2.86 per cent of gross national product (GNP).

In Europe, the biggest reductions in 1990-91 was in Germany, whose spending on industrial R\&D dropped by 2 per cent, and in Britain, where a fall of 7 per cent is blamed partly on cutbacks in defence R\&D. France, in comparison, increased its $R \& D$ spending by 1.2 per cent; but the total still fell from 2.41 to 2.40 per cent of GNP.

Among the middle-sized OECD countries, only Denmark and Austria achieved significant increases. Spending on R\&D in most of these remained roughly constant, although it fell by 6 per cent in Sweden.

D.D. focus for the curriculum, and greater specification of its essential teaching content.

The National Curriculum Council (NCC), in an interim response to these proposals two weeks ago, described them as a "marked improvement" on the current curriculum, but said they did not go far enough. In doing so, the NCC was responding to criticism from, among others, potential employers. This was expressed through organizations such as the Engineering Council, which has argued that technology courses should be strongly structured around manufacturing skills and industrial production.

Some teachers endorse this approach. But others complain that it is too narrow, and risks alienating precisely those who would benefit from increased familiarity with a range of technological processes, not merely those that belong to the factory or the office. "We argue that technology should be defined in the broadest possible way", says Sheila Denton, assistant secretary of the Association of Teachers and Lecturers.

The dilemma is epitomized by the issue of food technology. The Engineering Council argues that while certain aspects of food production "lie properly within technology", cookery and nutrition should be rescheduled as life skills. Home economics teachers, however, remain adamant that their subject has as important a role in teaching students to handle "soft materials" as engineering does in handling "hard materials" such as wood and metal - and thus legitimately belongs to the technology curriculum. "We believe that food repre-sents a user-friendly approach to the whole field of technological activities, using materials that are familiar to everyone", says Geoffrey Thompson, secretary of the National Association of Teachers of Home Economics.

Much will now depend on the direction in which Sir Ron Dearing, the chairman of the Schools Curriculum and Assessment Authority set up by the government to inquire into the future of the national curriculum, decides that the technology component should be steered. At present, the odds are on the Engineering Council's approach, which is supported by many school science teachers, concerned at what they see as a lack of theoretical underpinning to the current technology curriculum.

A final response from the NCC is due in the autumn, and the council says that the question of whether food should be included is still undecided. Meanwhile, the council has already agreed to provide schools with examples of technology projects "in a wider range of materials" than those currently being used. That could mean the return of traditional skills, such as woodwork and metal-working, and the consignment of soggy flapjacks to the education history books.

David Dickson 